
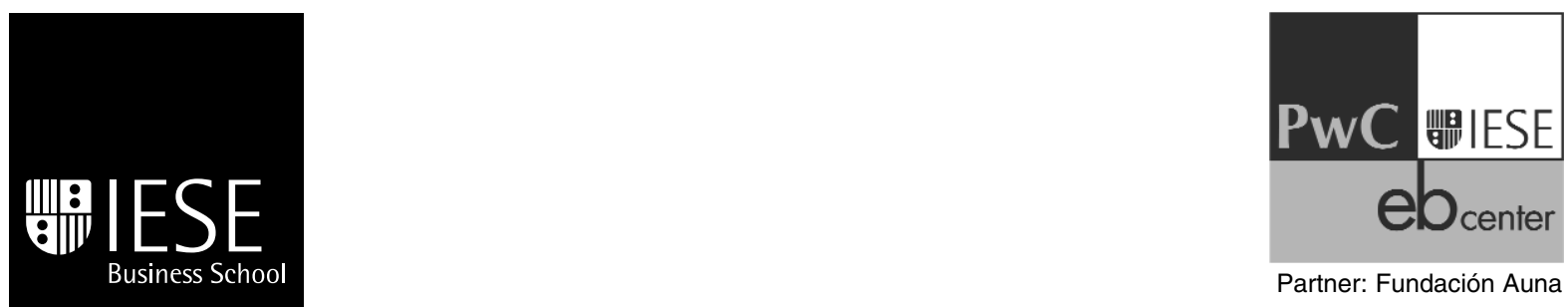

Partner: Fundación Auna

University of Navarra

\title{
MANAGING CUSTOMER SWITCHING COSTS: \\ A FRAMEWORK FOR COMPETING IN THE NETWORKED ENVIRONMENT
}

\author{
Mike Hess* \\ Joan Enric Ricart ${ }^{\star *}$
}

RESEARCH PAPER No 472

October, 2002

* Doctoral Candidate, IESE

** Professor of General Management, IESE

Research Division

IESE

University of Navarra

Av. Pearson, 21

08034 Barcelona - Spain 
The PwC\&IESE e-business Center is a joint initiative of IESE Business School and the professional services firm PricewaterhouseCoopers aimed at creating a Research Center to analyse the impact of e-business on organizations.

The mission of the PwC\&IESE e-business Center is to be an international benchmark for companies and universities in the development and communication of new ideas.

Based on this mission, the Center has set itself five basic goals:

1) Gather material on "best practices" and "next practices" in e-business.

2) Develop a conceptual framework that will help enable the world of business to understand and control the impact of the Internet and e-business.

3) Diffuse the knowledge generated by research in this field through the usual scientific and professional media.

4) Develop up-to-date, quality teaching materials.

5) Help train managers to understand the complexity of the changes that technology brings about in society and in the way businesses and competitive advantages are developed.

These goals will be achieved through three activities: research, training, and communication. The Center's efforts will be focused primarily on research, as the foundation for training and communication of the results obtained.

http://www.ebcenter.org 


\title{
MANAGING CUSTOMER SWITCHING COSTS: A FRAMEWORK FOR COMPETING IN THE NETWORKED ENVIRONMENT
}

\begin{abstract}
Previous research argues that customer switching costs play an important role in the firm's ability to retain customers and achieve competitive advantage. Research also indicates that in the increasingly networked environment, switching costs are changing in important ways. Despite switching costs' recognized role in contributing to competitive advantage and their increasingly strategic characteristics in the expanding networked environment, we find a lack of coherence and completeness in the conceptual tools and models developed to understand their role and help effectively manage the phenomenon. In this paper we attempt to address these needs by expanding and refining the conceptualization of switching costs and developing a more comprehensive framework for managers.
\end{abstract}

(Forthcoming in 2003 in Management Research)

Key words: customer switching costs, strategy, framework, networked environment. 


\section{MANAGING CUSTOMER SWITCHING COSTS: A FRAMEWORK FOR COMPETING IN THE NETWORKED ENVIRONMENT}

\section{Introduction}

The strategic management literature is focused on how firms can create and sustain competitive advantage. While researchers, consultants, and managers differ in the perspectives and approaches they have developed to achieve this goal, they are consistent in at least one aspect - their effort to successfully identify, understand, and manage the key strategic elements that lead to superior performance. A review of the strategy, economics, and marketing literature indicates that one of the more important strategic elements is a force known as customer switching costs (Porter 1980, 1985; Klemperer 1995; Kotler, 1997; Shapiro and Varian, 1999; Hax and Wilde II, 1999, 2001).

Customer switching costs are generally defined as costs that deter customers from switching to a competitor's product or service. These costs include elements such as the customers' time, effort, and knowledge that they invest in products, services, or relationships. While switching costs have always been considered an important element in achieving competitive advantage, research indicates that they are becoming even more strategic in the increasingly networked environment (Arthur, 1989, 1990, 1996; Economides, 1995; Yoffie, 1996; Bakos, 1997; Butler et al., 1997; Evans and Wurster, 1997; Shapiro and Varian, 1999; Hax and Wilde II, 2001). The unique characteristics of today's expanding networked environment - high-speed low-cost communications, digitalization, globalization, and the Internet - are impacting both the potential of switching costs and the strategies needed to achieve them.

Despite the fact that researchers have long recognized the existence and importance of switching costs, a review of the literature indicates a lack of coherence and completeness in the conceptual work that attempts to provide managers with better concepts, tools or models for effectively dealing with this increasingly strategic element. The aim of this paper, therefore, is to highlight the strategic role that customer switching costs play both in traditional sectors and in the expanding networked environment, to expand and improve upon the conceptualization of the force, and to develop a customer switching cost framework in an effort to improve understanding and management of this phenomenon.

The paper is organized as follows. In the first section we emphasize the strategic importance of customer switching costs by analyzing their role in the strategy, economics, and marketing literature. Next we explore why switching costs are even more strategic in today's networked environment. In the third section we discuss and expand upon the concept of

The financial support of the PwC-IESE eBusiness Center is gratefully acknowledged. 
customer switching costs in an effort to provide a more complete and useful conceptualization. Next we discuss the key issues and challenges involved in managing switching costs. In the fifth section we attempt to develop a switching cost framework to help improve understanding and management of these challenges. Finally, we discuss key implications of the paper and offer our conclusions. To simplify our discussion for the remainder of the paper, customer switching costs will be referred to simply as switching costs.

\section{The Strategic Importance of Switching Costs}

The strategic importance of switching costs has been recognized and researched by several academic disciplines, primarily strategy, economics, and marketing (Porter, 1980, 1985; Rumelt, 1987; Lieberman and Montgomery, 1988; Klemperer, 1987a, 1987b, 1995; Kotler, 1997; Shapiro and Varian, 1999; Hax and Wilde II, 1999, 2001). From the strategy perspective, Porter consistently discusses the importance of switching costs throughout his two seminal works, Competitive Strategy (1980) and Competitive Advantage (1985). In Competitive Strategy he explains that to achieve competitive advantage managers must understand the five basic competitive forces (1- threat of entry, 2- supplier power, 3- buyer power, 4- substitutes, and 5- rivalry) their businesses face within their industry and then to best position themselves to defend against the forces as well as to influence them in the company's favor. To understand and manage these forces, he emphasizes the need to go beyond just analyzing the forces to analyzing their underlying sources. He argues that it is the knowledge of these underlying sources that enables firms to create and implement the most effective competitive strategy, and he identifies switching costs as one of the key underlying sources affecting all five forces.

In a work by Hax and Wilde II (2001) called The Delta Project, the authors highlight the strategic role of switching costs by discussing the importance of customer bonding, a concept they define as a deep and powerful relationship with the customer. In their view "strategy - in both the new and the old economy - may be, and in many cases should be, formulated on the basis of bonding." If formulated and executed successfully, they add that these "customer focused options can create an unassailable competitive advantage."

Strategy work focusing on the areas of entrepreneurship and first mover advantage describes switching costs as key isolating mechanisms, impediments, or frictions that deter competitors from easily or immediately imitating the firm's innovation and appropriating its rent (Rumelt, 1987; Lieberman and Montgomery, 1988). Regardless of whether those firms achieved their first mover opportunity because of unique resources, foresight, or simply because of luck, it is argued that these isolating mechanisms enable such firms to exploit their position to enhance the size and duration of the first mover profits.

In the economics literature several researchers have studied the role of switching costs (Porter, 1980, 1985; Katz and Shapiro, 1985; Farrell and Saloner, 1986; Farrell and Gallini, 1988; Farrell and Shapiro, 1988; Klemperer, 1987a, 1987b, 1995; Shapiro and Varian, 1999; Shapiro, 2000). Klemperer uses theoretical models to show that in certain cases consumers face switching costs after choosing among products that were ex ante undifferentiated. As a result, in subsequent purchases rational consumers display brand loyalty when faced with a choice between functionally identical products. He claims that the role of switching costs, or the unwillingness of consumers to switch suppliers, can help to explain important aspects of firm competition, such as why it may be rational for managers to focus so much on market share. In their book Information Rules (1999), Shapiro and Varian emphasize that "switching costs are the norm, not the exception, in the information 
economy." They explain that "the way to win in markets with switching costs is neither to avoid lock-in nor to embrace it. You need to think strategically: look ahead and reason back."

In the marketing field, switching costs are identified as playing a key role in the process of creating strong customer loyalty (Kotler, 1997). This process, known as relationship marketing, involves all of the actions a firm can take to better understand and satisfy its customer. An important part of relationship marketing is attracting and retaining customers, as outlined below in the Customer-Development Process diagram (Figure 1). Kotler points out that there are two primary ways to retain loyal customers: increasing the level of customer satisfaction and raising switching costs.

Figure 1. The Customer-Development process

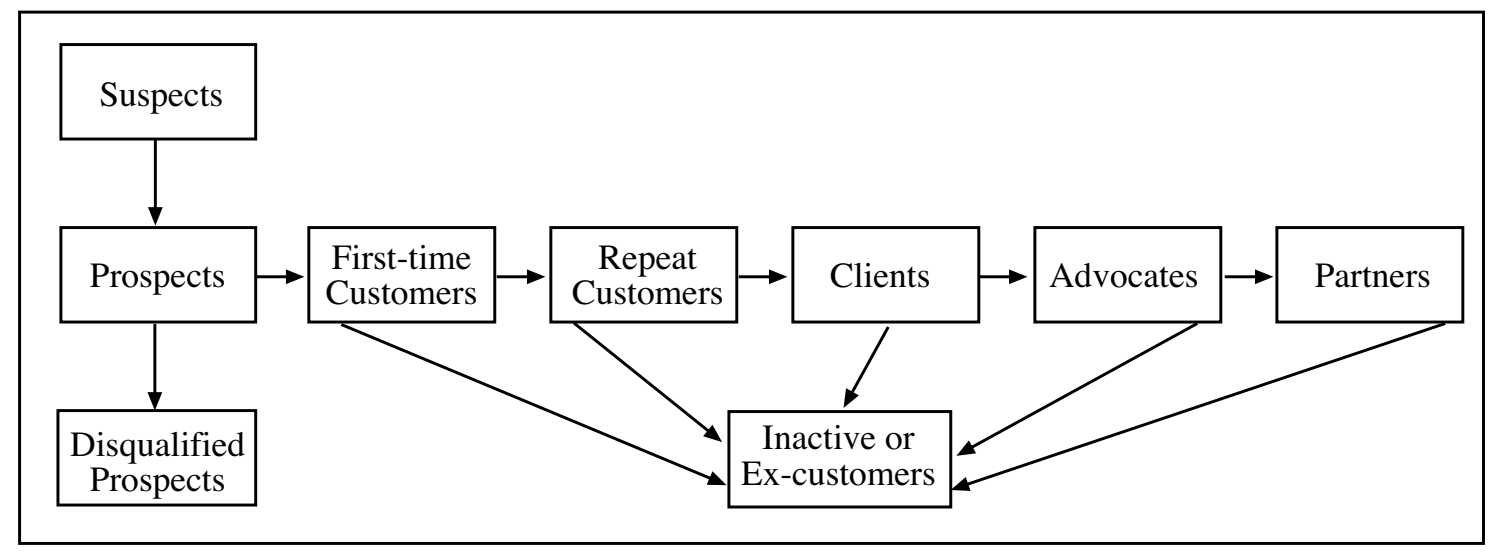

Source: Adapted from Kotler (1997), Griffin 81995), and Raphel and Raphel (1995).

Based on the literature reviewed we see that researchers in strategy, economics, and marketing clearly recognize the strategic importance of switching costs. Although the goal of creating and managing switching costs is described in various ways in the literature, the authors are consistent in emphasizing the need to understand and effectively manage this phenomenon. In the next section we explore how switching costs become even more strategic in today's competitive environment.

\section{Why Switching Costs are More Strategic in Today's Competitive Environment}

Many different strategies can be implemented to achieve switching costs, and many different strengths or degrees of switching costs can be obtained. The strategies and strengths available depend in large part on the context in which the firm competes. We find that several key changes brought on by the advances in technology and the growth in the use of the Internet make switching costs a more strategic force in today's competitive environment. These changes and their impact on switching costs are outlined below.

\section{Networks, Standards, and Switching Costs}

The first change is the growth in the use of the Internet and other computer and communications technologies. This growth has enabled the developed countries of the world to change from economies based on the processing of resources and raw materials to economies based on the processing of information, knowledge, and ideas (Arthur, 1996; 
Tapscott, 1997; Shapiro and Varian, 1999; Yoffie 1999; Gual and Ricart, 2001). This shift is important because as more and more economic activity is based on technology and information, and as firms and customers increasingly interconnect over the Internet's open standards, the world is increasingly becoming one large network.

While switching costs are an important force in all business environments, they are significantly more pronounced in network environments (Economides, 1998) because of a network's structure: it is composed of links that connect nodes, many different components make up the links and nodes, these components are complements to one another, and to be complementary the components must be compatible (Economides, 1996). In other words, the network works as a unified system. This system is built around a standard with which the components are made compatible. Because of this system structure and the need for participants in the network to have complementarity between components, network industries contain network externalities and positive feedback, also called increasing returns (Katz and Shapiro, 1985; Arthur, 1989; Shapiro and Varian, 1999).

The combination of these forces makes network industries high switching cost industries. Network externalities, also known as network effects or positive consumption externalities, exist when a user values a good or service more as the total number of users for that good or service increases. A common example is the fax machine - as more people own faxes, faxes become more valuable to each individual user. Positive feedback is a force that "makes the strong get stronger and the weak get weaker" (Shapiro and Varian, 1999). As Arthur (1990) describes, when a firm, product, or technology in a network industry gets ahead of the competition (whether by strategy or by chance), it tends to get further ahead, while one that is behind tends to get further behind. Such markets are described as tippy and often lead to a monopoly situation in which one firm takes over, or in other words, locks-in most or all of the market.

Because size and stability of market share matters in these markets, the key assets are not state-of-the-art manufacturing or raw materials but rather a locked-in installed base (Shapiro and Varian, 1999). The shift from the manufacturing economy to the information economy has forced many firms to focus on supply-side and demand-side economies of scale, as increasing returns exist alongside diminishing returns. The reason for this is that many of the high tech firms competing in network industries have unique cost structures - high fixed costs up front and minimal variable costs thereafter. For example, although Microsoft must spend millions of dollars to produce the first version of its operating system, reproducing it costs only pennies. Therefore, while most traditional manufacturing firms face diminishing returns (where variable costs fall only up to a certain point beyond which they begin to rise), many firms in the network industries enjoy this additional benefit of increasing returns which, according to Arthur (1996), "reign in the new, knowledge-based industries." Entire markets can become locked-in, he adds, and it is not necessarily the best product that wins.

In addition to understanding the role of switching costs between incompatible networks or standards as discussed above, where switching costs tend to be very high, it is important to understand the role of switching costs within a network or standard, where they tend to be much lower. For example, switching costs were high throughout the battle between video recorder standards Beta and VHS. Since a Beta owner's video collection could not be viewed with an incompatible VHS recorder, and vice versa, customers faced high switching costs when switching recorder standards. Once VHS established itself as the industry standard, the battle between standards disappeared, leaving only competition within the standard. The switching costs for changing among different VHS brands were extremely low because several manufacturers produced nearly identical products and customers' video collections could now be used with all video recorder brands. 
Another reason it is important to understand switching costs' role within a network is because in certain network industries only one standard exists from the outset. For example, competitors may collaborate to agree upon a single standard up front, and then compete within this standard for market share. A good example of this is the Global System for Mobile Communications (GSM) technology agreed upon throughout Europe as the standard for mobile network operators. Since no operator owns the standard, all operators have to compete within the open standard to win market share. Switching costs for changing operators within this common standard are fairly low because any GSM user can communicate with any GSM user, regardless of the operators involved. Thus, once a standard is set, whether through a competitive battle or an upfront collaboration, switching costs among brands within the network tend to be much lower than switching costs among brands in incompatible networks.

\section{Switching Costs: Increasing or Decreasing?}

There is ongoing debate over switching costs' role in the Internet environment, where switching costs are often referred to as friction. According to Hax and Wilde II (2001), the networked environment has altered the nature of competition by amplifying the relationship between customers and suppliers. While switching costs are not a new force, they argue that the combination of a common digital language and the reach of the network make switching costs more strategic and powerful in the new economy. They state that "the Internet is all about bonding," and that as a result we can expect more friction, or switching costs, not less in the new economy.

Shapiro and Varian (1999) argue that frictions do not disappear in the Internet environment, they just mutate into new forms. This enables firms to convert traditional markets into lock-in markets by creating information-enabled or synthetic switching costs, for example loyalty programs. Firms are also expanding their reach and providing more personalized information and products. In addition, while switching costs based on equipment tend to decline as equipment wears out or superior performing equipment comes along to replace it, switching costs based on information (such as Amazon.com's customer databases) never wear out. In fact, they tend to strengthen over time given that the more information a company has about the client, the better the company can serve the client and thus further increase switching costs.

In an empirical study by Amit and Zott (2001), switching costs are found to play an important role in e-businesses' ability to create value. The authors carry out multiple case studies on U.S. and European firms and conclude that the four value creators of e-business are: 1) efficiency, 2) novelty, 3) complements, and 4) lock-in. Their data reveal that firms achieve lock-in as a result of switching costs and network externalities, and that the strategies implemented to manage lock-in include loyalty programs, establishing dominant design proprietary standards, establishing trustful relationships, learning, customization and personalization, and virtual communities.

It is important to recognize, however, that not all of the changes in the new economy are leading to an increase in switching costs. The same changes in technology that provide firms with opportunities to create new switching costs are enabling customers and competitors to reduce traditional ones. For example, the traditional trade-off between richness (depth and detail of information) and reach (number of customers firms can reach and number of products they can offer) is being blown up (Evans and Wurster, 1999). These authors explain that information is being separated from things and that this information is now accessible to millions of people who are communicating through universal, open 
standards. This connectivity is critical, they argue, because key strategic elements such as brand identity, customer loyalty, and switching costs all rely on various types of information. They argue that traditional value chains will deconstruct because better informed customers will find it easier to switch suppliers, thus reducing traditional advantages such as vertical integration (one-stop shopping) or established relationships.

The blow-up of the tradeoff between richness and reach leads to several important changes - reductions in search costs, reductions in transaction costs, reductions in interaction costs, reductions in asymmetries of information, and an increase in choice. Each of these changes causes bargaining power to shift from sellers to buyers (Bakos, 1997; Butler et al., 1997; Evans and Wurster, 1999; Porter, 2001). New infomediaries, navigators, and online communities further promote this shift in power by providing customers with more detailed, timely, and objective information, and allowing larger numbers of buyers and sellers to interact with one another (Armstrong and Hagel III, 1996; Evans and Wurster, 1999; Hagel III and Singer, 1999). Hartman and Sifonis (2000) go so far as to say that in today's competitive environment traditional customer relationship management is out because it is the customer who now manages the relationship. Therefore, customers must be listened to and valued, and if the business does everything right, only then might the customer agree to be served.

Shapiro and Varian (1999) recognize that new technologies can shift bargaining power by reducing search costs and enabling sellers to send out more messages and reach wider audiences. But they caution that switching costs may remain prohibitive because customers still have to filter through and evaluate all of the offers. Yoffie (1999) provides an additional message of caution to the frictionless proponents by claiming that because of the bewildering pace of the Internet, the traditional core elements of competitive advantage such as leadership, innovation, quality, customer lock-in, and switching costs - may become even more important. Brynjolfsson and Smith (2000) support Yoffie's claim in a study on Internet price dispersion among commodity goods. The authors found that while many dimensions of friction do decline in the Internet environment, other friction creating factors such as trust, brand, and awareness may even become more important on the Internet.

In this section we have shown that customer switching costs take on an increasingly strategic role in the expanding networked environment. Some of the researchers reviewed here claim that switching cost opportunities are declining, while others argue that switching costs are actually increasing in variety and strength as a result of the Internet. We believe that both arguments are valid. On the one hand, several traditional sources of switching costs have been reduced or in some cases even eliminated because of the characteristics of the networked environment. At the same time, some new switching cost opportunities have been created and certain traditional ones have become much more powerful in the changing environment. Because both increases and decreases in switching costs are taking place, and because of their potential impact on firm performance, recognizing and understanding these changes is critical for successful strategic decision making in today's competitive environment.

\section{Conceptualizing Switching Costs}

While researchers have provided a great deal of insight into and understanding of switching costs, we believe important aspects can be improved and expanded upon to strengthen the conceptualization of the term. In the remainder of this section we discuss these aspects and then, building on previous work, we present what we believe is a more comprehensive and refined definition. 
The researchers reviewed earlier in this paper concur that a range of switching costs exists that can impact a firm's competitive advantage (Porter 1980, 1985; Klemperer 1995; Kotler, 1997; Shapiro and Varian, 1999; Hax and Wilde II, 1999, 2001; Amit and Zott, 2001). However, their lack of agreement on the specific switching costs makes it difficult to clearly identify and understand the full range of switching cost opportunities that firms must manage.

In Porter's view, "switching costs are fixed costs incurred by the buyer when it changes suppliers", to which he later adds, they are "costs that potentially arise from all the impacts a substitute has on the buyer's value chain" (1985). Therefore, he emphasizes the potential investments that the customer would need to make due to switching as opposed to investments already made. Klemperer, on the other hand, explains that "a switching cost results from a consumer's desire for compatibility between his or her current purchase and a previous investment" (1995). Therefore, his emphasis is based more on previous investments the customer has made. Finally, the conceptual work of Shapiro and Varian (1999) offers a more balanced perspective of switching costs as a mixture of both past and potential investments, but they do not always provide a clear distinction between the two. In light of these different perspectives, we believe clarification is needed to distinguish between switching costs created by previous investments and switching costs created by potential investments.

The other key conceptual aspect of switching costs that we feel can be enhanced is their scope. We do this in two ways. First, we add a switching cost type called network switching costs within the Previous Investments (PI) category. Network (PI) switching costs arise due to the investment the customer makes in becoming a member of a network. While memberships have always existed, participation within networks, particularly virtual networks, has exploded due to the growth in the use of the Internet. The second scope enhancement involves adding a third category of switching costs that we label Opportunity Costs (OC). As opposed to the other two categories of switching costs, which result from past or potential investments, opportunity costs represent opportunities the customer would forego if he or she switched brands. Thus, switching costs are opportunities that the customer had with the previous brand that he or she would no longer have with the new brand, even though the customer had never invested directly in those opportunities prior to the time of switching. We identify two types of switching costs within the opportunity costs category: 1) network, and 2) complements.

The switching cost that creates network (OC) switching costs involves the cost of leaving a network which the customer could have participated in and benefited from. For example, if a customer of America Online (AOL) switches to a different online service provider (OSP) he or she would forego the opportunity to participate in the network (for example, virtual communities) along with AOL's 30 million plus subscriber base, even though the customer had never invested in participating prior to the time of switching.

The switching cost that creates complements switching costs involves foregoing the opportunity to benefit from the range of complementary products and services available for one's current brand. For example, a customer of a Palm handheld computer who switches to a competitor's incompatible handheld computer would forego the opportunity to benefit from the wide range of Palm-compatible software, even if no investment had been made to purchase or learn how to use such software prior to the time of switching. Although both network (OC) and complements switching costs have always existed, their presence has increased significantly in the information-based economy, especially as a result of the Internet.

We believe that combining the three categories of switching costs discussed above creates a more comprehensive and useful conceptualization of the term. In the left-hand column of Table 1 below we list the three general types of switching costs: 1) previous investments, 2) potential investments, and 3) opportunity costs. Within each of the general 
categories we indicate the range of specific types of switching costs that are possible. In the right-hand column we describe each of the particular switching costs. Because the different types of switching costs can and most often do combine to create higher degrees of switching costs, separating them in practice is not as easy as it is here. However, for analytical purposes we find it is useful to distinguish among them to provide a clear understanding of the full range of switching cost opportunities that firms must be aware of.

Table 1. Classifications of Customer Switching Costs

\begin{tabular}{|c|c|}
\hline Type of Switching Cost & Description of Switching Cost \\
\hline $\begin{array}{l}\text { 15t Category: } \\
\text { Previous Investments }\end{array}$ & $\begin{array}{l}\text { This type of switching cost results from investments the customer has already } \\
\text { made in the current brand. }\end{array}$ \\
\hline Durable Purchase & $\begin{array}{l}\text { Investments made in a durable product, the value of which exists for the } \\
\text { economic lifetime of the product. }\end{array}$ \\
\hline Complementary Purchase & $\begin{array}{l}\text { Investments made in complementary products that are compatible with the durable } \\
\text { equipment previously purchased. }\end{array}$ \\
\hline Relationship & Investments made to develop relationships with suppliers. \\
\hline Learning/Training & Investments made to learn how to use a particular brand. \\
\hline Search Costs & $\begin{array}{l}\text { Investments made to learn about the characteristics of a particular brand and to } \\
\text { find the right supplier. }\end{array}$ \\
\hline Specialized Supplier & Investments made in specialized products from a single supplier. \\
\hline Loyalty Programs & $\begin{array}{l}\text { Investments made in previous purchases of the brand as part of a frequent } \\
\text { purchase program that results in accumulated discounts. }\end{array}$ \\
\hline Information and Database & $\begin{array}{l}\text { Investments in saving information and/or creating databases in a particular } \\
\text { brand of software technology. }\end{array}$ \\
\hline Psychological & $\begin{array}{l}\text { The psychological cost of having to give up a brand that the customer simply } \\
\text { likes and therefore feels loyal to for non-economic reasons. }\end{array}$ \\
\hline Network & $\begin{array}{l}\text { Investments made in becoming a member of a network (such as a virtual } \\
\text { community or chat group) which may include learning and relationship building. }\end{array}$ \\
\hline $\begin{array}{l}2^{\text {nd }} \text { Category: } \\
\text { Potential Investments }\end{array}$ & $\begin{array}{l}\text { This type of switching cost results from investments the customer would or } \\
\text { could have to make if he or she wants to switch to a different brand. }\end{array}$ \\
\hline Durable Purchase & The cost of having to make a new durable purchase. \\
\hline Complementary Purchase & $\begin{array}{l}\text { The cost of having to make new complementary purchases (if previously } \\
\text { purchased complements are not compatible with the new durable purchase). }\end{array}$ \\
\hline Relationship & The cost of having to develop new relationships with a new supplier. \\
\hline Learning/Training & The cost of having to learn how to use the new brand. \\
\hline Search Costs & The cost of having to find a new brand and supplier. \\
\hline Contractual Commitment & $\begin{array}{l}\text { The cost of having to pay a penalty for breaking a legal commitment to purchase a } \\
\text { certain amount of a brand over a certain length of time from a specific supplier. }\end{array}$ \\
\hline Risk of Failure & The risk that the new brand will not perform as expected. \\
\hline Switching Back Costs & $\begin{array}{l}\text { The cost of having to switch back to the previous brand if the new brand proves } \\
\text { unsatisfactory. }\end{array}$ \\
\hline $\begin{array}{l}\text { 3rd Category: } \\
\text { Opportunity Costs }\end{array}$ & $\begin{array}{l}\text { This type of switching cost results from the opportunities the customer would } \\
\text { forego if he or she were to leave the current brand. }\end{array}$ \\
\hline Network & $\begin{array}{l}\text { The cost of leaving a network even if one has not yet invested in becoming an } \\
\text { active member. }\end{array}$ \\
\hline Complements & $\begin{array}{l}\text { The cost of giving up the benefit of a range of complementary goods and/or } \\
\text { services that exist exclusively for the customer's current brand even if the } \\
\text { customer has not yet invested in or used such complements. }\end{array}$ \\
\hline
\end{tabular}

Source: Adapted from Porter (1980, 1985), Klemperer (1995), Shapiro and Varian (1999), and Hax and Wilde II (2001). 
In addition to distinguishing among the different types of switching costs, it is important to recognize that within each type, different degrees of switching costs are possible. We suggest the concept of "degrees of switching costs" as a useful way of capturing this idea (Figure 2). For one, switching costs are not static. Rather, they are almost always changing either up (strengthening) or down (weakening) the continuum.

Figure 2. Conceptualizing Degrees of Switching Costs

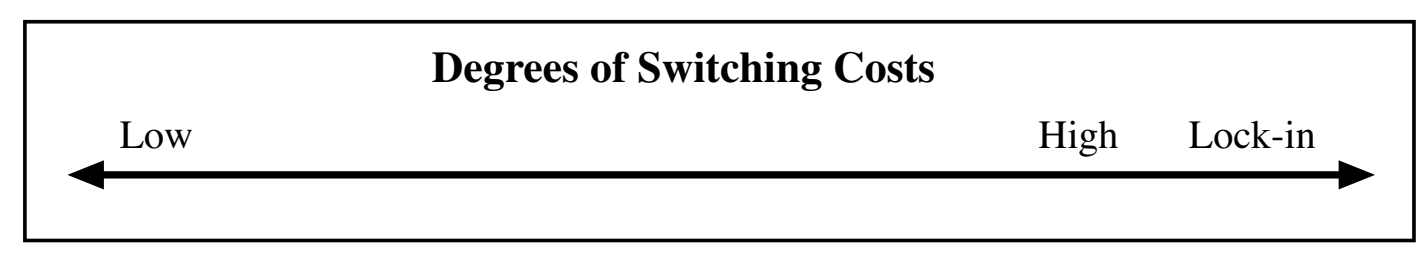

Secondly, at any one point in time, firms will have customers at many different stages along the continuum. And third, positioning lock-in at the extreme of the continuum is fitting because lock-in is an extreme or exceptional case. Few firms will achieve locked-in customers; it is almost always a question of degree. Thus, using the term 'degrees of switching' costs helps to ensure that these dynamic qualities of switching costs are recognized and understood.

\section{Switching Costs and Competitive Advantage}

To finalize our discussion on the conceptualization of switching costs, it is useful to discuss how they relate to competitive advantage. The two generally accepted strategies for achieving competitive advantage are low-cost and differentiation (Porter, 1985): either the firm operates with lower costs than competitors, or provides a product or service with unique or superior features that the customer values, or some combination of the two. In his discussion on differentiation, Porter emphasizes the important role that switching costs have in enhancing the firm's differentiation. He argues that if a firm can develop switching costs at the same time that it differentiates, it will increase its ability to achieve superior performance and build a more sustainable competitive advantage.

We believe that switching costs can combine with either differentiation or low-cost strategies to enhance the firm's competitive advantage. In addition, we argue that switching costs on their own can provide the firm with competitive advantage, even when the firm is unable to achieve or maintain low-cost or differentiation.

First of all it is important to point out that low-cost and differentiation are not forms of switching costs, so neither is included in Table 1 above. In other words, each of these two strategies can create competitive advantage whether switching costs exist or not. However, if switching costs are generated by the firm along with either one or the other of these strategies, the firm's competitive advantage will be more sustainable. In addition, if after successfully generating switching costs the firm's low-cost or differentiation advantage is eliminated by competitors or other external factors, the switching costs may enable the firm to sustain its competitive advantage. 
First we can look at the case of low-cost and differentiation in the absence of switching costs. In the case of the low-cost leader, if a competitor comes along and offers the same product or service but at a lower price, or offers the same price but with a differentiated product or service, we can assume that the customer will switch brands. Likewise, in the case of the differentiated offer, if a competitor comes along offering a similarly differentiated product or service at a lower price or a better differentiated product or service at the same price, we can assume that the customer will switch brands.

Because firms face a constant threat from competitors attempting to match or exceed cost and differentiation advantages, the successful generation of switching costs can play a key role in strengthening and sustaining competitive advantage, whether that advantage was initially achieved through low-cost, differentiation, or both. For example, if the low-cost firm is also able to generate switching costs, then the firm increases its chances of retaining customers even if competitors eventually match or beat their price (depending, of course, on the degree of the price difference versus the degree of switching costs generated). Similarly, if the firm offering differentiated products or services generates switching costs, it too will increase its chances of retaining customers if competitors match or exceed its offering (again, retention will depend on the relative difference between the brands' prices and differentiation).

We are not suggesting that firms should pursue a strategy based solely upon switching costs, ignoring low-cost and differentiation. Such a strategy is not likely to provide any competitive advantage, or at least not likely to provide a sustainable competitive advantage. The firm must provide a minimum degree of competitiveness in price and differentiation relative to competitive brands. What we are suggesting is that the firm need not necessarily be the "leader" in price or differentiation to achieve and maintain a competitive advantage. No firm can achieve leadership in these two dimensions indefinitely. Switching costs are therefore a key strategic complement to these two strategies that, if managed effectively, can enable firms to build a more sustainable competitive advantage.

Figure 3 summarizes the conceptual work discussed in this and the previous section. The shaded box represents the networked environment - the context in which the switching cost opportunities exist. The arrows show that these opportunities determine the degree of switching costs that the firm is potentially able to achieve. This continuum represents the fact that the customers' degree of switching costs will range from low to high. At the far right, when a customer's switching costs are extremely high, the customer is considered locked-in to the brand. 
Figure 3. Conceptualizing Customer Switching Costs

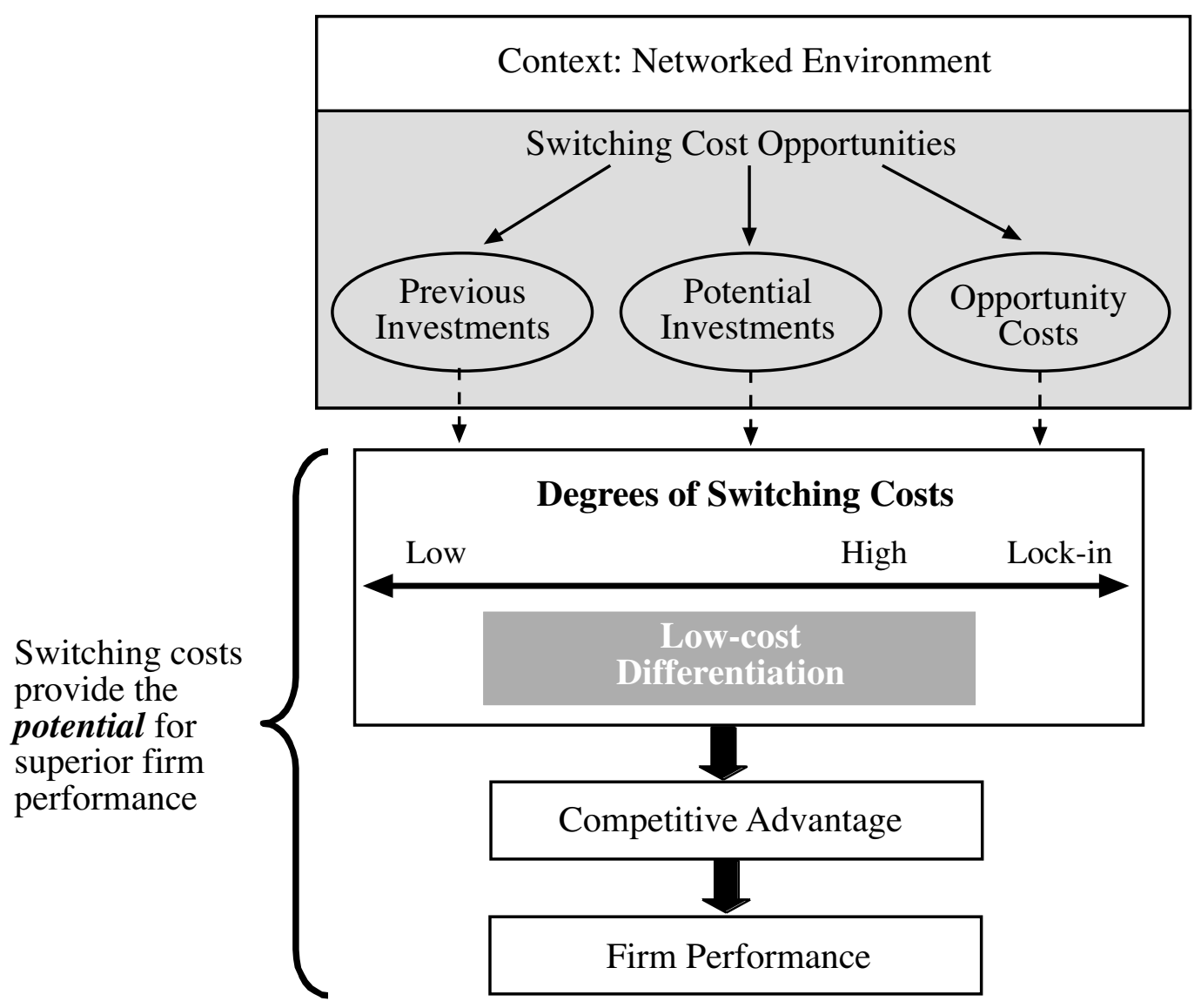

The degree of switching costs achieved combines with the firm's strategies of lowcost and/or differentiation to determine the firm's ability to create and sustain a competitive advantage, which ultimately determines the firm's performance. However, we provide a note of caution in Figure 3 to emphasize that generating switching costs merely provides the potential for superior performance, not a guarantee. This dose of caution is necessary because achieving switching costs, and achieving them in a way that provides superior performance, is a complex challenge involving many different strategic issues. In the next section we identify and discuss the key issues involved.

\section{Key Issues in Managing Switching Costs}

With a clear and comprehensive conceptualization of switching costs in place, the next step towards building the framework is identifying the key issues involved in managing switching costs. Our analysis of these issues is not intended to be exhaustive. Rather, we focus on the key issues discussed in the literature.

One important issue involved in managing customer switching costs is determining the firm's switching cost opportunities based on its strategic positioning. In the Triangle Model developed by Hax and Wilde II $(1999,2001)$, the authors emphasize the importance of recognizing the different strategic positions available to the firm, the unique characteristics of 
each position, and the implication these characteristics have in determining the firm's ability to generate switching costs and "bond" with customers (Figure 4).

Figure 4. The Triangle Model

\begin{tabular}{|l|l|l|}
\hline Best Product & Total Customer Solutions & System Lock-In \\
\hline $\begin{array}{l}\text { Strategy focused on the product's } \\
\text { economics: }\end{array}$ & $\begin{array}{l}\text { Strategy focused on the customer's } \\
\text { economics: }\end{array}$ & $\begin{array}{l}\text { Strategy focused on the system's } \\
\text { economics: } \\
\text { Reducing customer costs or } \\
\text { increasing customer profits } \\
\text { Complementor lock-in, } \\
\text { competitor lock-out, and } \\
\text { proprietary standards }\end{array}$ \\
$\begin{array}{l}\text { Switching costs based on the } \\
\text { intrinsic superiority of the } \\
\text { product or service }\end{array}$ & $\begin{array}{l}\text { Switching costs based on a wide } \\
\text { offering that satisfies most if } \\
\text { not all of customer's needs, } \\
\text { especially through close proximity } \\
\text { to customer, learning about the } \\
\text { customer (customization) and } \\
\text { learning by the customer (time } \\
\text { invested) }\end{array}$ & $\begin{array}{l}\text { Switching costs based on } \\
\text { understanding the entire } \\
\text { architecture of the system, } \\
\text { especially nurturing, attracting, } \\
\text { and retaining complementors }\end{array}$ \\
\hline
\end{tabular}

Source: Adapted from Hax and Wilde II $(1999,2001)$.

The authors identify three main strategic positions available to the firm: best product, total customer solutions, and system lock-in. In the best product position, strategy is focused on the product's inherent characteristics of either low-cost, differentiation or both. In the total customer solution position, strategy is focused on the customer's characteristics or activities, and the firm attempts to provide products and/or services that best meet the customer's needs. Finally, in the system lock-in position, strategy is focused on the system's characteristics, in other words, the focus is on other key elements that make up the firm's system. The main elements in this case are the complements (1) of the firm's product or service, for example complementary software that works with computer hardware. Although the three strategies are not mutually exclusive, and a business could decide on a blended strategy, the authors explain that distinguishing among them provides a useful way of understanding and analyzing the different bonding strategies available.

Estimating the future revenues of the customer, also referred to as valuing the installed base, is recognized as another key issue in managing switching costs (Porter, 1980; Klemperer, 1987a; Shapiro and Varian, 1999). This effort involves segmenting customers when possible and then comparing total switching costs (switching costs for competitors' customers, start-up costs for new customers) with the anticipated net present value of revenues (NPVR) per customer. If the total switching costs (customer's plus company's) (2) involved in acquiring a customer are less than the anticipated NPVR, then the company should invest in acquiring the customer; otherwise the customer is not a profitable target.

(1) A product is considered a complement to your product if by using it the user values your product more. A product is considered a competitive product if by using it the user values your product less.

(2) Company switching costs include costs facing the firm such as finding new customers and the costs of adding them to their database. 
Another switching cost challenge involves managing the tradeoff between attracting new customers and leveraging existing ones (Porter, 1980; Klemperer, 1995; Shapiro and Varian, 1999). The tradeoff is caused by the desire to reduce prices to attract new customers and grow market share, on the one hand, and the desire to raise prices to harvest profits from existing customers, on the other. Because of this tradeoff, once firms develop an installed base with switching costs they are limited in their ability to deter entry (Klemperer, 1987; Farrell and Shapiro, 1988; Lieberman and Montgomery, 1988). This creates second mover advantages for firms with no installed base who are willing to attract new users with lower prices.

To deal effectively with this tradeoff, customer perceptions must be carefully managed so that potential customers do not get scared off and existing customers do not feel taken advantage of. One method is to create competitors by licensing "second-sources" (Shapiro and Varian, 1999; Garud and Kumaraswamy, 1993; Farrell and Gallini, 1988). With the existence of competition, the threat of rendering the buyer hostage to a monopoly supplier is reduced (Williamson, 1975). The obvious risk is that firms are arming their competition. However, in certain circumstances, the only chance to establish a market is some form of coopetition (3) - to collaborate with competitors in growing the market, then competing with these same competitors in attracting loyal customers (Brandenburg and Nalebuff, 1996).

One model that helps explain the process involved in managing some of these switching cost issues is the Lock-In Cycle developed by Shapiro and Varian (1999). This model describes the process of customer lock-in in high-tech industries, identifying four sequential phases of the lock-in process: 1) brand selection, 2) sampling, 3) entrenchment, and 4) lock-in, then back to brand selection to repeat the cycle (Figure 5). They insist that managers must not only anticipate the four stages of the cycle, they must also anticipate the long-term effects on their customers as they pass through the cycle over and over again. To effectively manage this cycle, they suggest that firms focus on three principles: 1) invest build up the installed base, 2) entrench - increase customer switching costs, and 3) leverage maximize the value of the installed base.

Figure 5. The Lock-In Cycle

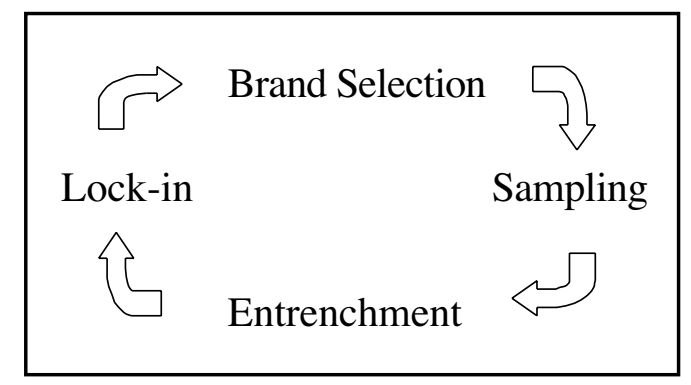

Source: Shapiro and Varian, 1999.

(3) The term coopetition was coined by Ray Noorda, a founder of Novell, which is a networking software company. 
Finally, a key problem in managing switching costs is that firms themselves become locked-in to current successful practices, resulting in a reluctance or inability to anticipate change or lead innovation (Hartman and Sifonis, 2000; Christensen, 2001). Farrell and Saloner (1986) describe this inertia as the installed base effect, which occurs when firms inhibit users from switching to a superior standard because of the network externalities that exist with the current standard. Yoffie (1996) calls this reluctance to innovate the tyranny of the installed base. He explains that a firm's current assets become its future liabilities or core rigidities (4) if it does not develop a willingness and capability to change. In high tech industries, he adds, history shows that firms hesitant to innovate for fear of cannibalizing their own business will soon be overtaken by other firms who have no such fear.

Shapiro and Varian (1999) have developed a Compatibility - Performance diagram that describes the innovation challenge involved in managing switching costs (Figure 6). This diagram was developed to explain the strategic options of firms competing in standards wars by distinguishing between two alternatives - evolution and revolution. If a company's offering remains compatible with the current offering or industry paradigm, the authors classify the strategy as evolutionary. Although there is likely to be an improvement in the offering, it is based on the same elements as the previous offering. In this case, compatibility takes priority over performance in an effort to strengthen the current customer switching costs.

Figure 6. The Compatibility versus Performance Diagram

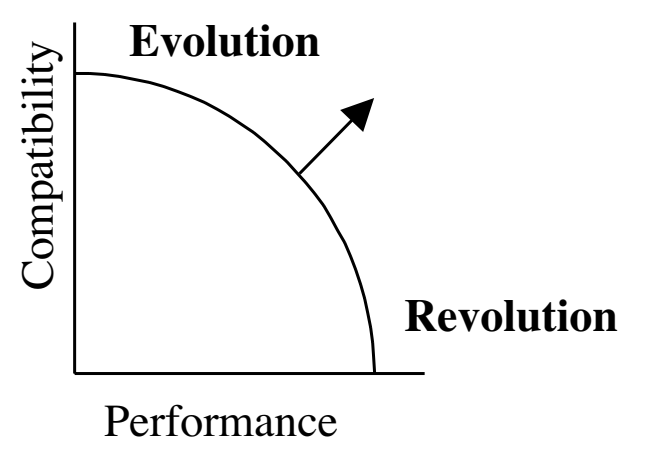

Source: Shapiro and Varian, 1999.

If a company's offering is far superior yet incompatible with the current offering or industry paradigm, the authors classify the strategy as revolutionary. In this case performance takes priority over compatibility, which tends to eliminate existing switching costs in pursuit of entirely new ones. Although combinations of these two strategies are also possible, a trade-off is usually unavoidable. The authors argue that understanding and managing this tradeoff is key to managing the migration path of the company's customers.

In this section we have discussed the key challenges researchers have identified and tools they have developed to help understand and manage switching costs. In the next section we build upon this existing work in order to develop a new framework.

(4) Leonard-Barton describes traditional core capabilities that inhibit innovation as core rigidities. 


\section{The Switching Cost Framework}

Effectively managing the switching cost issues discussed throughout the paper is a complex challenge. In this section we attempt to address this challenge by developing a switching cost framework. To develop our framework we build upon our conceptual work and the broad range of switching cost issues and tools discussed. To address all of these aspects in a structured and coherent manner, the switching cost framework is built around three interrelated levels: 1) the strategic level, 2) the innovation level, and 3) the operational level (Figure 7). The netted background of the framework in Figure 7 symbolizes the fact that switching costs must be managed within an increasingly networked environment. In the remainder of this section we discuss the key aspects of the framework.

Figure 7. The Customer Switching Cost Framework

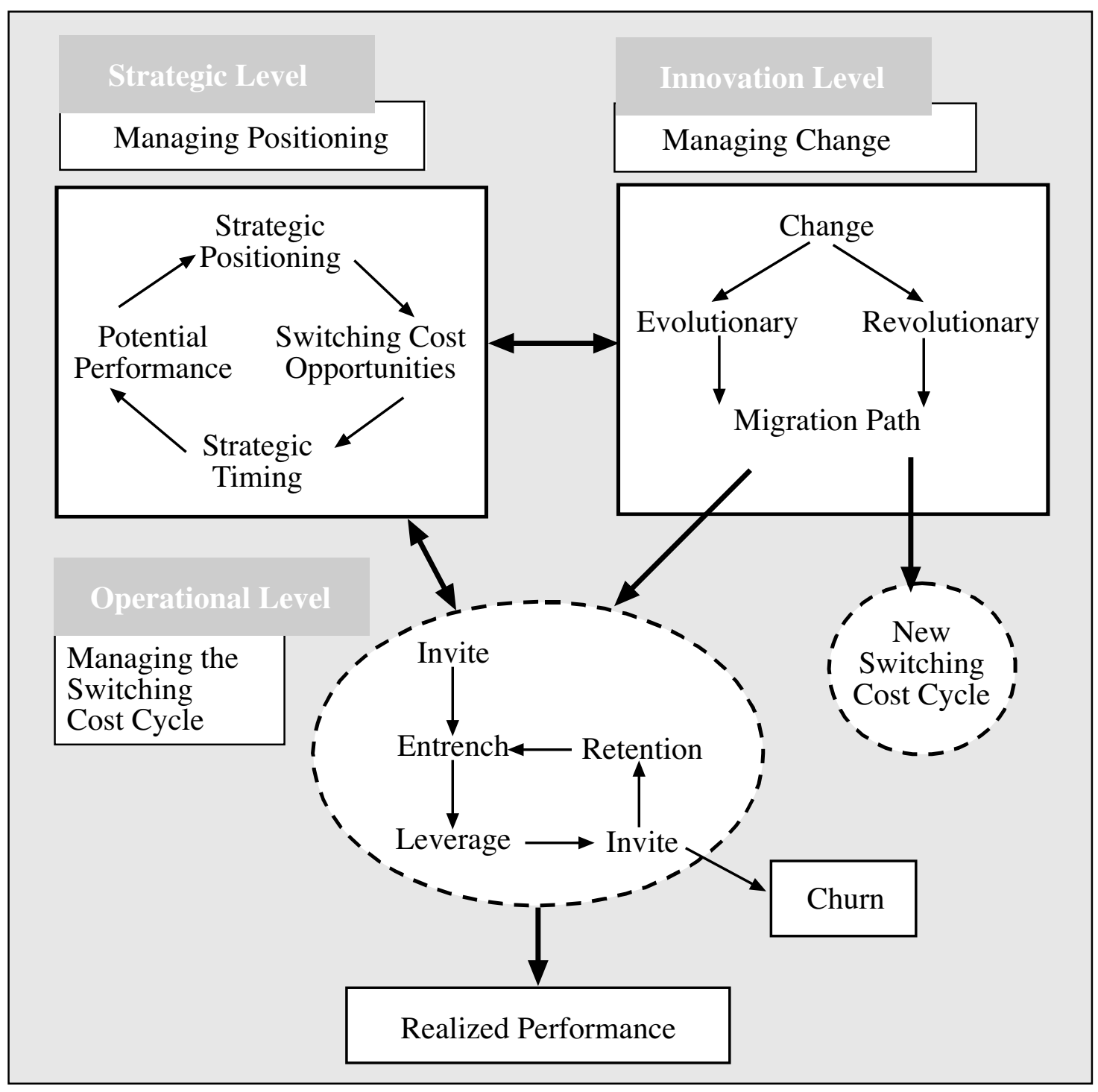




\section{Strategic Level}

Managing switching costs begins at the strategic level, at which the firm is striving to maximize its potential performance. We build this level around a strategic positioning cycle that involves four steps: 1) strategic positioning, 2) identifying and aligning switching cost opportunities, 3) strategic timing, and 4) estimating potential performance. In the first step, the firm determines if its strategic positioning will emphasize product, customer, or system economics, or some combination of the three, which follows the logic of the Triangle model (Figure 4) described earlier. While these three strategic positions are not mutually exclusive, their respective switching cost opportunities are based on different strategic factors and therefore it is useful to understand and distinguish among them. Nonetheless, firms can shift from one position to another or expand from one position to include different combinations of two or three positions.

\section{Identification and Alignment of Switching Costs}

Determining the firm's strategic positioning lays the groundwork for the next step of this level: identifying and aligning the full range of switching cost opportunities available to the firm. Our classification of switching costs in Table 1 enables managers to identify all of the opportunities that they can pursue. While the classifications we provide are generic, firms can make them specific by adapting them appropriately to their particular business, competitive environment, and industry. Once the opportunities are identified and specified, firms need to attempt to align the opportunities with the three strategic positions.

Although aligning opportunities with positions is not an exact science, it is a valuable exercise because it forces managers to analyze the switching cost opportunities available within their chosen positioning strategy. Such insight can help firms to determine if they are well positioned or if in fact they need to rethink their strategic positioning. In Figure 8 , we have aligned the generic switching cost opportunities with the three strategic positions.

Figure 8. Strategic Positioning and Corresponding Switching Cost Opportunities

\begin{tabular}{|c|c|c|c|c|}
\hline \multirow[b]{2}{*}{$\begin{array}{c}\text { Strategic } \\
\text { Positioning }\end{array}$} & Best Product & \multicolumn{2}{|c|}{ Total Customer Solutions } & System Lock-In \\
\hline & $\begin{array}{l}\text { Product Economics: } \\
\text { Focusing on } \\
\text { the product's } \\
\text { and/or service's } \\
\text { characteristics }\end{array}$ & \multicolumn{2}{|l|}{$\begin{array}{l}\text { Product Economics: } \\
\text { Focusing on the } \\
\text { customer's } \\
\text { activities or needs }\end{array}$} & $\begin{array}{l}\text { Product Economics: } \\
\text { Focusing on the } \\
\text { elements of the firm's } \\
\text { system or network, } \\
\text { especially complements }\end{array}$ \\
\hline $\begin{array}{l}\text { Switching } \\
\text { Cost } \\
\text { Opportunit }\end{array}$ & Psychological & $\begin{array}{l}\text { Relationship* } \\
\text { Training/Learning* } \\
\text { Contractual Commitmen } \\
\text { Loyalty Program } \\
\text { Search Costs* } \\
\text { Risk of Failure } \\
\text { Switching Back Costs } \\
\end{array}$ & $\begin{array}{l}\text { nt } \\
\text { Durab } \\
\text { Inforn } \\
\text { Specic } \\
\text { Netwo }\end{array}$ & $\begin{array}{l}\text { Complementary Purchase } \\
\text { Complements } \\
\text { Network (OC) }\end{array}$ \\
\hline
\end{tabular}

- Network (PI) refers to network switching costs in the Previous Investment classification.

- Network (OC) refers to network switching costs in the Opportunty Cost classification.

- * Refers to switching cost opportunities that can exist as either past investments, potential investments, or both. 
Table 2 explains the logic behind the way we have aligned the different switching cost opportunities. In the left-hand column are the strategic positions. In addition there are two rows entitled overlap to account for the switching cost opportunities that we believe overlap more than one strategic position. In the right-hand column we align the different switching cost opportunities. Because we are aligning switching cost opportunities, rather than just switching costs, we explain our alignment logic from the firm's perspective as opposed to the customer's perspective. This is consistent with the fact that the framework is designed to help firms strategically pursue and manage switching cost opportunities.

Table 2. Logic of Alignment of Switching Cost Opportunities with Strategic Positioning

\begin{tabular}{|c|c|}
\hline Strategic Positioning & Logic of Alignment of Switching Cost Opportunities \\
\hline \multicolumn{2}{|l|}{$\begin{array}{l}\text { Best Product (BP) } \\
\text { Focusing on } \\
\text { the product's } \\
\text { and/or service's } \\
\text { characteristics }\end{array}$} \\
\hline $\begin{array}{l}\text { (BP) } \\
\text { Overlap } \\
\text { (TCS) }\end{array}$ & $\begin{array}{l}\text { Psychological - create a brand image that the customer wants to be associated with } \\
\text { (BP); bond with the customer in some intangible way that fulfills a need or desire } \\
\text { (TCS). }\end{array}$ \\
\hline $\begin{array}{l}\text { Total Customer } \\
\text { Solution (TCS) } \\
\text { Focusing on the } \\
\text { customer's activities } \\
\text { or needs }\end{array}$ & $\begin{array}{l}\text { Relationship - create a personal relationship with the customer, independent of the } \\
\text { product or the system. } \\
\text { Training/Learning - train or encourage the customer to invest in learning how to use } \\
\text { the brand. } \\
\text { Contractual Commitment - convince the customer to commit to a legal agreement. } \\
\text { Loyalty Program - offer awards based on the customer's volume of use or duration } \\
\text { with the brand. } \\
\text { Search Costs - make it difficult to compare your brand with competitors' brands. } \\
\text { Risk of Failure - convince customers that the risk of failure or dissatisfaction is high if } \\
\text { they switch to a competitors' brand. } \\
\text { Switching Back Costs - reduce the costs involved for former customers to switch } \\
\text { back to your brand if their new brand does not sufficiently satisfy their needs. }\end{array}$ \\
\hline (TCS) & $\begin{array}{l}\text { Durable Purchase - encourage the customer to invest in durable equipment that satisfies } \\
\text { his or her needs (TCS); encourage investment in multiple compatible pieces of } \\
\text { equipment (SLI). }\end{array}$ \\
\hline Overlap & $\begin{array}{l}\text { Information and Databases - encourage customer's dependence upon and customized } \\
\text { use of software (TCS); encourage use of software in a variety of settings; make the } \\
\text { software only compatible with or exclusive to your equipment (SLI). }\end{array}$ \\
\hline (SLJ) & $\begin{array}{l}\text { Specialized Supplier - encourage customers to collaborate in developing equipment } \\
\text { that best meets their needs (TCS); make equipment part of a larger specialized or } \\
\text { proprietary system or network (SLI). }\end{array}$ \\
\hline (2) & $\begin{array}{l}\text { Network (PI) - build and/or provide access to a network that satisfies the customer's } \\
\text { needs (TCS); encourage customers to invest in becoming active members of the } \\
\text { network (SLI). }\end{array}$ \\
\hline $\begin{array}{l}\text { System Lock-in (SLI) } \\
\text { Focusing on the elements } \\
\text { of the firm's system or } \\
\text { network, especially } \\
\text { complements }\end{array}$ & $\begin{array}{l}\text { Complementary Purchase - encourage the customer to invest in complements to the } \\
\text { durable purchase. } \\
\text { Complements - offer a range of complements to the customer's initial purchase that } \\
\text { the customer will want to utilize and not want to forego. } \\
\text { Network (OC) - build and/or provide access to a network that the customer will want to } \\
\text { participate in and will not want to forego. }\end{array}$ \\
\hline
\end{tabular}

- Network (PI) refers to network switching costs in the Previous Investment classification.

- Network (OC) refers to network switching costs in the Opportunity Cost classification. 
Our alignment of the different switching cost types shown in Figure 8 and described in Table 2 highlights some interesting results. The first observation that stands out is the fact that we align no switching cost opportunities directly within the best product (BP) position. The only exception is psychological costs, which overlaps with this position. This is because the customer who chooses the brand from a firm in this strategic position does so based on the product's economics - either its low-cost or differentiation. As we discussed earlier, these two dimensions are not switching costs. Rather, they are strategies that can be complemented and strengthened by switching costs. Thus, aside from psychological switching costs, the remainder of the switching costs are aligned with the other two strategic positions.

The second key observation is that the total customer solutions (TCS) position offers the broadest range of switching cost opportunities based on our alignment logic. In addition to the seven types which we align solely with the TCS position are the additional types of switching cost opportunities that overlap with the other two positions. It is also important to note that many of these opportunities (relationships, loyalty programs, networks, information and databases, etc.) are enhanced by the characteristics of the expanding networked environment that we discussed in section 2 of this paper.

Finally, the main switching cost types aligned within the system lock-in (SLI) position are centered on complements and networks. While the range of switching cost opportunities is not as large as that of the TCS position, the resulting degree of switching costs can be very powerful if the firm succeeds with such strategies. As in the TCS position, several of the opportunities aligned with the SLI position (complements, network, etc.) are clearly enhanced in a networked environment.

\section{Illustrating the Framework: Telefonica Móviles de España}

Telefonica Móviles de España (TME), the country's leading mobile network operator (MNO), provides us with a useful example to help illustrate the framework. While TME is active in all three strategic positions, its main switching cost opportunities exist in the TCS and SLI positions. For example, in the TCS position TME can pursue relationships switching costs through its customer service, call centers and retail distribution centers. Another opportunity aligned with TCS is TME's loyalty program, in which customers are rewarded for their longevity and volume of use. In the SLI position TME can pursue network opportunities that encourage customers to invest in calling plans (i.e., encouraging families and friends to all choose TME's network in order to reduce tariffs on calls to one another) or chat/special interest groups that are exclusive to TME users. Another SLI opportunity available to the operator is complements, in which TME's customers have access to a range of complementary products (such as exclusive content) and services (such as exclusive location based services) (5).

\section{Timing}

The next step at the strategic level is to analyze the role of timing. As we discussed earlier, first mover advantages can be strengthened by switching costs (Rumelt, 1987; Lieberman and Montgomery, 1988). Thus, firms must recognize their timing status (first

(5) Location-based services are mobile services that make use of the customer's present location. For example, the MNO can provide the customer with information about local hotels, restaurants, or directions. 
mover, second mover, latecomer) and then analyze how this impacts their strategic positioning and switching cost opportunities. Continuing with our example above, TME clearly had a large first mover advantage due to its previous monopoly status. Apart from this advantage, however, TME has been the pioneer in bringing new technologies to the market, such as being the first to offer SMS (6), the first to provide national GPRS (7) coverage, and the first to offer a loyalty program (MoviStar points). While first mover advantages have helped enable TME to dominate the battle for new customers (attracting 55\% of all new users in 2001), its switching cost management is enabling the firm to retain its customers. Thus, even if TME's competitors (Vodafone or Amena) respond by matching TME's product or service offering (for example, by offering similar national GPRS coverage), TME is likely to retain its current customers because of the switching costs it has had time to generate. On the other hand, while TME has been leveraging its large installed base for years, Spain's latecomer MNO Amena entered the market in 1999 with zero installed base. Since Amena faced no tradeoff between attracting and leveraging customers, it was willing to compete for new customers with more aggressive pricing than TME, which, as a result of its first mover success in building up an installed base, had less desire to lower prices.

\section{Potential Performance}

In the final step of the strategic positioning cycle the firm estimates its potential performance. This estimation is based on the three previous steps of the cycle (positioning, switching cost opportunities, and timing), as well as its valuation of the installed base as discussed in section 4. If the firm is satisfied with its estimated potential performance, then it may not need to adjust the other steps of the cycle for the time being. If, on the other hand, the firm is dissatisfied with its estimated potential performance, this analysis prompts managers to reassess the firm's strategic positioning, switching cost opportunities, and timing in order to enhance such projections.

\section{Innovation Level}

The second level of the framework is the innovation level. To effectively manage switching costs, firms must either drive change through innovation, or anticipate and react to change through adaptation. Standing still for too long can be dangerous. We call this process managing the migration path, a path that can be either evolutionary or revolutionary.

The innovation level in our framework applies to compatibility (evolution) or performance (revolution), building on the compatibility-performance diagram discussed in section 4. However, in our framework we are concerned with a brand's compatibility or incompatibility with the existing competitive paradigm, which may or may not be a standard. In other words, managing the migration path applies to both standard and non-standard industries, products, and services.

The importance of the innovation level is that it forces businesses to recognize the need for managing switching costs with a long-term perspective. It helps firms to recognize

(6) Short Messaging Services are short text messages that mobile phone users can send to one another in place of making a phone call.

(7) General Packet Radio Service is a step between GSM and 3G cellular networks. It enables faster transmission using the GSM network, allowing always-on, higher capacity, Internet-based content and packet-based data services. 
that some changes are evolutionary, in which case the firm can maintain its focus on existing switching cost opportunities. The arrow pointing from the innovation level to the operational level represents evolutionary change, in other words, change that firms can adapt to while continuing to compete within the same switching cost cycle. The innovation level also makes clear that switching costs are subject to disruption that can be driven by the firm, the firm's rivals, or a range of exogenous forces. Revolutionary changes can unlock the firm's installed base, in which case the firm may have to focus on entirely new switching cost opportunities. The arrow pointing to the "new switching cost cycle" represents revolutionary change, in other words, change that requires firms to shift to a new switching cost cycle.

A mixture of both evolutionary and revolutionary changes is affecting the Spanish MNOs and their switching cost opportunities. These changes center around: 1) user habits, 2) technology, 3) regulation, and 4) new participants. Changing user habits involve a shift from postpay to prepay agreements and an increasing use of data versus voice when communicating. While both of these changes have until now been evolutionary, data usage could soon become revolutionary based on the second of our four changing elements technology. Thus, while technology's evolutionary changes (WAP (8), SMS, and GPRS) have not radically altered the industry, its revolutionary changes (UMTS (9) [3G (10)] and the Internet) probably will. Our third changing element, regulation, is causing only evolutionary changes. These changes include number portability (which enables users to switch operators and to take their phone number with them) and the opening up of the market to MVNOs (11). Finally, regarding new participants, the appearance of global MNOs (Vodafone) and the potential appearance of MVNOs are evolutionary changes. However, new participants such as WLANs (12), PDAs (13), handset manufacturers, and software manufacturers are potentially revolutionary changes.

\section{Operational Level}

This third level of the framework focuses on the key operational steps that must be managed within the context of the changing environment (innovation level) to fulfill the strategic objectives (strategic level). We describe the operational process of managing switching costs as the Switching Cost Cycle. The cycle represents a dynamic process which involves five stages: 1) invite, 2) entrench, 3) leverage, 4) invite again, and 5) retention or churn.

The first invite stage represents the first time that the customer decides to purchase a particular brand (or sign a contract). To successfully invite or attract new customers, firms normally have to make investments that are referred to as customer acquisition costs (CAC)

(8) Wireless Application Protocol is an open, global specification that makes information accessible to mobile users who use mobile phones, pagers, two-way radios, etc.

(9) Universal Mobile Telecommunication Standard is the 3G technology adopted in Europe and in some areas of the U.S.

(10) 3rd Generation mobile technology enables high-speed mobile access to Internet Protocol (IP)-based services.

(11) Mobile Virtual Network Operators compete by leasing infrastructure from MNOs and then offering mobile services with their own branding to customers.

(12) Wireless Local Area Networks are on-premise data communication systems that work on publicly available radio spectrum and eliminate the need for wired connections. They are typically located in "hot-spots" such as hotels and airports where business travelers need access.

(13) A Personal Digital Assistant is a small hand-held computer. 
or subscriber acquisition costs (SAC). Determining how much to invest is based on the potential performance estimations made at the strategic level. TME's CACs include advertising and sponsoring of events to create an attractive brand image, subsidizing the customer's handset purchase, and eliminating contract customers' fees and minimum spending requirements.

Once the customer has made a purchase or signed a contract, the firm moves on to the second stage of the cycle - entrench. Exactly how the firm will strive to entrench its customers has already been determined at the strategic level when the firm identified its switching cost opportunities. Therefore, at this stage the firm is carrying out those opportunities or strategies to increase customer switching costs. If the firm manages this stage of the cycle effectively, it greatly increases its chances of retaining customers later on in the cycle and thus of realizing the potential performance targeted at the strategic level.

As discussed earlier, the main entrenchment opportunities involve encouraging the customer to make investments in the brand. For example, through its loyalty program MoviStar Points, TME offers prizes to its customers based on their volume of use and longevity as customers. In addition, it offers exclusive chat and special interest groups and customizable content (Reuters WAP Premium) (14) that customers have to learn how to use and that are only available to TME customers.

Other entrenchment strategies involve building attractive complements and networks for the brand. TME's large installed base (55\% of the market) generates both complements and network switching cost opportunities. The large installed base is a valuable complement because as the number of customers increases, the value of TME's network for its customers increases (network externalities). The following two examples help to illustrate why. First, more customers means more chat and special interest groups, which increases the likelihood a user will find the topic, group, or person they want to interact with. Second, joining the largest installed base increases the customer's probability of making inter-network calls and therefore of reducing calling charges because calling within an operator's network is typically cheaper than calling between operators' networks due to interconnection charges (15).

Not only does the firm begin to try and entrench the customer once he or she has made an initial purchase, but strategies to leverage the customer may begin at once as well. In other cases, leveraging may not occur immediately, as the firm may decide to wait until it has achieved what it believes to be a sufficient level of entrenchment with the customer. In the case of TME, its leveraging strategies focus on encouraging customers to increase usage, to pay for premium services, and to shop online. In the framework, leverage is intentionally positioned as one of five stages in the ongoing switching cost cycle. This forces firms to focus on managing the tradeoff that we discussed in section 4 of the paper. In other words, firms must consider how their leveraging activities will impact: 1) their ability to invite new customers that are watching how it treats existing customers, and 2) their ability to retain customers at the next stage - invite for the second time.

This second invite stage, which is the fourth in the cycle, is the stage at which the firm's existing customer must decide if he or she will repurchase the firm's brand (or renew a

(14) Reuters WAP Premium is an exclusive content service that TME offers through its partnership with Reuters Group. The premium content consists of high quality news offered in real time.

(15) Interconnection charges are the charges operators add to calls that are initiated by a user from another operator's network but that terminate with a user from their own network. 
contract). In fact, from the moment the initial purchase has been made, the firm is strategically inviting the customer through entrenchment strategies to stay with the brand. In most cases, regardless of the degree of switching costs achieved with the customer up to this stage, the firm needs to make some type of investment once again to invite the customer to repurchase. If the firm has successfully identified and managed entrenchment opportunities, then not only should the cost of this second invitation be much lower than the initial customer acquisition costs, but the chances of the customer making a repeat purchase should also be greater.

For example, TME allows its customers to exchange their accumulated MoviStar points for new handsets as a way to keep customers. Because these points are based on a customer's past spending with TME, the customer is indirectly contributing to the cost of the phone. In addition, costs are further reduced in the form of the reduced risk TME faces when dealing with a known customer. When TME offers a free or subsidized phone to a new customer, TME must bear the full cost of the phone or subsidy, thus increasing the cost of the invitation. In addition, because TME cannot know in advance how new customers will behave, costs increase due to the risk that such customers will not generate revenues.

If the repeat purchase is made, customer retention (stage 5) is achieved and the cycle continues: the firm further entrenches the customer, the firm continues leveraging the customer, and another invitation is made to repeat the purchase once again. If the stages leading up to the second invite stage are not managed effectively, the chances are greatly reduced that a repeat purchase will be made. The situation in which no repeat purchase is made is described as customer turnover or customer churn (stage 5). Customers that churn either switch to a competitor's brand or stop using the product or service altogether. The main focus is on customers that switch to a competitor's brand because they are generating ongoing revenues - but for someone else. In other words, these are customers who still value the product or service, but who have switched brands because their switching costs, or at least their perceived switching costs, were not high enough for the initial firm to retain them. Investments to invite back churned customers are often made, especially to valuable customers. These types of investments can be costly and thus, even if successful, diminish the firm's realized performance.

\section{An Integrated Framework}

While each of the three levels of the framework plays a significant role in the management of switching costs, focusing on just one or even two of the levels would not provide a complete approach. By integrating them, the framework ensures that the issues from all three levels are understood and addressed. In addition, integration ensures that key relationships among the three levels are understood. These relationships are outlined below.

First is the relationship between the strategic and operational levels. The two-way arrow shows that each level influences the other. At the strategic level, the positioning and switching cost opportunities identified will determine the entrenchment strategies, while the potential performance targets will help determine how much the firm should invest when inviting customers.

At the operational level, the firm's ability to retain customers will help it to determine if its strategic positioning and corresponding switching cost opportunities are viable. For example, if TME's retention rate is lower than expected, it will be prompted not only to reevaluate its execution of the switching cost cycle, but also to reevaluate its 
switching cost opportunities identified at the strategic level in an effort to understand the cause of customer churn. TME could find that competitors are offering to honor accumulated MoviStar points when customers switch from TME to their brands. As a result, TME will not be able to enhance switching costs with its points program, regardless of how effectively the program is executed throughout the cycle. Not only does the framework help TME to reach such a conclusion, it also prompts the firm to adjust its strategic positioning so that it focuses on viable switching cost opportunities and avoids an over-dependence on those in decline or those that no longer exist.

Second is the relationship between the strategic and innovation levels. The two-way arrow indicates that each level influences the other. On the one hand, the firm's own strategic positioning can proactively determine if the migration path is evolutionary or revolutionary. TME's pioneering of a loyalty program (MoviStar points), SMS, and GPRS station bases are changes that clearly affect the Spanish market, though more or less in an evolutionary way. However, once TME's 3G base stations are utilized by the mass market, it may be able to drive revolutionary change with multimedia offerings and intentionally shift the competitive playing field to a new switching cost cycle. Thus, rather than merely adjusting its position in reaction to or in anticipation of exogenous changes, TME can drive the change endogenously and force its competitors to adapt their migration paths accordingly.

On the other hand, the context or environment in which the firm competes needs to be continually analyzed by the firm to effectively manage positioning and switching cost opportunities. If change appears evolutionary, positioning will be relatively stable and the customer's switching cost opportunities will remain relatively intact. However, if change is or could become revolutionary because of competitors' strategies or other changes such as the Internet, a new migration path may be necessary, which in turn could force the firm to adjust its strategic positioning and opportunities. TME's investments in $e$-moción (its WISP) (16) and Terra Mobile (its wireless portal) demonstrate that it is actively repositioning itself in anticipation of the major change that will occur when $3 \mathrm{G}$ technology makes the mobile Internet a reality. TME recognizes that when these technologies finally become mainstream for mobile users, switching cost opportunities will shift from those based almost entirely on voice services to those based increasingly on multimedia services.

Finally there is the relationship between the operational and innovation levels. The one-way arrow here indicates that the innovation level influences the operational level, but not vice versa. If change (whether endogenous or exogenous) is evolutionary, the firm's migration path will be to continue competing within the same competitive paradigm (in other words, the same switching cost cycle) and to continue building upon most if not all of the existing switching costs. An evolutionary change in the Spanish market such as the entrance of a global MNO, in this case Vodafone (the world's largest MNO), definitely intensifies competition. Nonetheless, the competitive paradigm (MNOs versus MNOs) remains essentially the same as it was prior to Vodafone's entrance, thus TME can continue building on the same switching costs that it already had established.

The innovation level's impact on the operational level is very different if new participants are capable of revolutionizing the market. For example, if either Nokia (the world's leading handset manufacturer) or Microsoft (the world's leading software manufacturer) succeed in their quest to gain control of the software running on the mobile phone screens of TME's customers, TME risks being delegated to the role of a faceless

(16) Wireless Internet Service Provider. 
infrastructure provider. Thus, these new participants threaten to shift the wireless communication industry to a new competitive paradigm, in which many new or perhaps entirely new switching costs would have to be developed. In other words, TME may have to switch to a new switching cost cycle to remain competitive.

As we have seen in this section, the framework that we have developed provides a useful tool for identifying and analyzing the key switching cost issues as well as the relationships among them. Although applying the framework thoroughly to TME is a process that goes beyond the scope of this paper, our illustration offers an idea of how the framework can be applied and the types of insight it can generate.

\section{Discussion and Management Implications}

We have argued in this paper that customer switching costs play a key role in competitive strategy and that their role is changing in important ways as a result of the increasingly networked environment. We also claim that managing switching costs is much more complex than simply raising switching costs. We show that they are a very dynamic force and that managing them involves many difficult challenges: managers need to understand what types of switching cost opportunities are available in their chosen strategies; they need to try and understand the potential strength, or degree, of the different switching cost opportunities they plan to pursue; they need to recognize how switching costs are changing as a result of the increasingly networked environment; they need a long-term strategic approach for developing switching costs; they need to innovate or quickly adapt to changes to ensure the maintenance of switching costs over time. By expanding and refining the conceptualization of switching costs and developing a switching cost framework, we believe that this paper contributes to addressing these challenges.

Our conceptualization of switching costs contributes by clarifying, unifying, and expanding upon this key strategic element. First, we have shown that while switching costs have long been considered an essential element for achieving competitive advantage, differences exist as to how it is portrayed in the literature. By clarifying the different approaches to switching costs we then are able to unify them in order to develop a more comprehensive and understandable conceptualization of the phenomenon. In addition to unifying the existing conceptual work, we expand the concept of switching costs to include three new types of switching costs. While these new switching costs do not arise solely due to the characteristics of the networked economy, we argue that they are definitely more prominent because of this changing environment. Furthermore we argue that the changing environment is affecting almost all switching costs in important ways that must be recognized. Whether or not firms can or want to capitalize on these changes, at least they need to be aware of them.

In addition to conceptualizing the specific types of switching costs, we also contribute to the general conceptualization of the phenomenon by suggesting the idea of "degrees of switching costs". We feel it is useful to conceive of switching costs in this way for several reasons. For one, the different switching cost opportunities enable firms to generate different degrees of switching costs. In addition, each of the opportunities pursued will generate different degrees of switching costs with customers over time. Finally, the idea of degrees expands the switching cost discussion well beyond the unusual case of "lock-in". Lock-in may be what all firms are striving for, but in reality it is a situation few firms achieve. Most firms are to be found battling continuously somewhere along the switching 
cost continuum, either striving to increase or decrease the degree of switching costs they have with customers, depending on the situation. Thus, the idea of degrees of switching costs provides a more realistic approach to this phenomenon and enables us to apply the concept to a broader range of situations and industries.

The development of the switching cost framework provides several important contributions as well. First of all, it highlights the important role of switching costs in the firm's strategy and performance, a role emphasized consistently throughout the strategy, marketing, and economics literature that we reviewed. The framework explicitly links switching costs to the firm's strategic positions at the strategy level. It also explicitly links switching costs to firm performance at two different levels. At the strategy level, switching costs are linked to the performance the firm can potentially achieve, while at the operational level, switching costs are linked to the performance the firm actually achieves based on its ability to effectively manage the switching cost cycle.

The second important contribution of the framework is the guidance it gives in understanding and dealing with the changing strategic role of switching costs as a result of the increasingly networked environment. Although there is debate over the direction in which switching costs may be changing, researchers consistently agree that change is occurring. Thus, while switching cost and lock-in economics have always been present, their form or appearance tends to change in the networked environment. By guiding a detailed analysis of switching costs, the framework helps firms to recognize when and how switching costs are changing. It also helps firms to recognize when switching costs and lock-in are capable of creating monopolies (though perhaps only temporary monopolies) and locking-in markets due to the existence of networks, network externalities and positive feedback.

Third, the framework enhances the analysis and management of switching costs by ensuring that the analysis has a sufficient degree of depth, breadth, time-span, and integration. First, distinguishing among the three levels (strategic, innovation, and operational) ensures the necessary depth by enabling firms to recognize and analyze the three levels separately. Second, including the three levels in one framework enables firms to capture the breadth necessary in managing switching costs, as all three levels need to be accounted for. Third, by 'time-span' we mean to say that the framework emphasizes the need to take a long-term view to managing switching costs. The idea of the 'migration path' in the innovation level along with the idea of 'cycles' in the other two levels force managers to think long-term. Finally, the framework's emphasis on integration ensures that firms go beyond a deep, broad, and long-term analysis of switching costs to include a dynamic analysis of the interrelationships between the different levels.

We believe that only by integrating the analysis of the framework's three levels along these four dimensions can switching costs be well understood and managed. Thus, while each of the existing tools we have discussed in the paper makes a positive contribution to understanding and managing switching costs, each is limited on its own precisely because of a lack of such integration. Each of them effectively addresses the issues it was designed to address, but none of them was designed to provide a complete framework for managing switching costs, thus a new framework was needed.

Fourth, we believe this new framework provides a powerful and in our view necessary strategic lens that can enable new insights and emphases when combined with other strategy tools or perspectives. Thus, when analyzing the industry, competitors, or key resources and capabilities using existing approaches, the switching cost lens complements these approaches by prompting managers to recognize and manage switching costs' role in achieving competitive advantage. 
In addition to applying the switching cost lens to their own business, we suggest that firms apply the lens to their value net. Brandenburg and Nalebuff (1996) describe the value net as a map of all of the players involved in the competitive game and their relationships with one another. The five players include the business, competitors, suppliers, customers, and complementors. By applying the lens to each of the players, the firm will improve its understanding of switching costs' role throughout its entire value net, which in turn should enhance its ability to effectively manage switching costs, to manage relationships with these players, and to improve performance.

The conceptualization and development of the framework should reinforce the efforts made by other researchers to direct managers' attention to the importance of proactively managing switching costs. While we believe this work contributes to the understanding of this strategic element, more research clearly needs to be done. For one, due to the lack of empirical work and theoretical development on switching costs, there is a need to do more of both. One approach is to conduct multiple case studies to explore the role of switching costs empirically and to compare findings from different settings. This would be a logical progression with which we could evaluate the theoretical ideas put forth in this paper. In addition, we see an opportunity for more cross-fertilization among the fields of research discussed in this paper, especially between strategy and marketing. Each of these fields provides valuable insight on switching costs and combining efforts should further enhance our understanding.

Finally, switching costs are still often viewed in the literature as an abusive or opportunistic behavior on the part of suppliers and as a problem for captive customers (Gallini and Karp 1988). Obviously the potential for suppliers to behave opportunistically towards customer with high switching costs will always exist. However, the rapid pace and scope of change in today's competitive environment increase the opportunities for revolutions to occur that can unlock customers. As a result, today's opportunistic firms run the risk of being locked-out by customers in the future.

\section{Conclusion}

In this paper we have attempted to improve the understanding and management of an important strategic element known as customer switching costs. By reviewing the strategy, economics, and marketing literature, we show that researchers have long acknowledged the importance of the phenomenon. In addition, we discuss how switching costs appear to be changing as a result of the increasingly networked environment. Despite broad recognition of its important and changing strategic role, we find a lack of coherence and comprehensiveness regarding the conceptualization of switching costs and the tools or models provided to manage the force. To address these issues we attempt to build upon and refine the term's conceptualization and we develop an integrated switching cost framework. We believe that the switching cost framework provides a powerful and insightful lens for managers pursuing competitive advantage in today's networked environment. $\square$ 


\section{References}

Amit, R., \& Zott, C. (2001). Value creation in e-business. Strategic Management Journal, 22, 493-520.

Armstrong, A., \& Hagel III, J. (1996). The real value of on-line communities. Harvard Business Review, 74(3), 134-141.

Arthur, W.B. (1989). Competing technologies, increasing returns, and lock-in by historical events. Economic Journal, 99, 116-131.

Arthur, W.B. (1990). Positive feedbacks in the economy. Scientific American, 262, 92-99.

Arthur, W.B. (1996). Increasing returns and the new world of business, Harvard Business Review, 74(4), 100-108.

Bakos, Y. (1997). Reducing buyer search costs: Implications for electronic marketplaces. Management Science, 43(12), 1676-1692.

Brandenburger, B., \& Nalebuff, A. (1996). Co-opetition. New York: Currency Doubleday.

Brynjolfsson, E., \& Smith, M.D. (2000). Frictionless commerce? A comparison of internet and conventional retailers. Management Science, 46(4), 563-585.

Butler, P., Sahay, A., Mendonca, L., Manyika, J., Hanna, A., \& Auguste, B. (1997). A revolution in interaction. The McKinsey Quarterly, 1, 4-23.

Christensen, C. (2001). The past and future of competitive advantage. Sloan Management Review, 42(2), 105-109.

Economides, N. (1995). Network externalities, complementarities, and invitations to enter. The European Journal of Political Economy, 12, 211-232.

Economides, N. (1996). The economics of networks. International Journal of Industrial Organization, 14(6), 673-699.

Economides, N. (1998). Competition and vertical integration in the computing industry. In J.A. Eisenach \& T.M. Lenard (Eds.), Competition, innovation, and the role of antitrust in the digital marketplace. Boston, MA: Kluwer Academic Publishers.

Evans, P., \& Wurster, T.S. (1999). Blown to bits. Boston, MA: Harvard Business School Press.

Farrell, J., \& Shapiro, C. (1988). Dynamic competition with switching costs. RAND Journal of Economics, 19(1), 123-137.

Farrell, J., \& Saloner, G. (1986). Installed base and compatibility: Innovation, product preannouncements, and predation. The American Economic Review, 76(5), 940-955.

Farrell, J., \& Gallini, N.T. (1988). Second-sourcing as a commitment: Monopoly incentives to attract competition. The Quarterly Journal of Economics, 19(1), 123-137. 
Gallini, N., \& Karp, L. (1988). Sales and consumer lock-in. Economica, 56, 279-294.

Garud, R., \& Kumaraswamy, A. (1993). Changing competitive dynamics in network industries: An exploration of Sun Microsystems' open systems strategy. Strategic Management Journal, 14, 351-369.

Griffin, J. (1995). Customer loyalty: How to earn it, how to keep it. New York: Lexington Books.

Gual, J., \& Ricart, J.E. (2001). Estrategias empresariales en telecomunicaciones e internet. Madrid: ELR.

Hagel III, J., \& Singer, M. (1999). Unbundling the corporation. Harvard Business Review, $77(2), 133-141$.

Hartman, A., \& Sifonis, J.G. (2000). Net ready: Strategies for success in the e-conomy. New York: McGraw-Hill Publishing Company.

Hax, A.C., \& Wilde II, D.L. (1999). The delta model: Adaptive management for a changing world. Sloan Management Review, 40(2), 11-28.

Hax, A.C., \& Wilde II, D.L. (2001). The delta project. New York: Palgrave.

Katz, M.L. \& Shapiro, C. (1985). Network externalities, competition, and compatibility. American Economic Review, 75, 424-440.

Klemperer, P. (1987a). Markets with consumer switching costs. Quarterly Journal of Economics, 102, 375-394.

Klemperer, P. (1987b). The competitiveness of markets with switching costs. RAND Journal of Economics, 18(1), 138-150.

Klemperer, P. (1995). Competition when consumers have switching costs: An overview with applications to industrial organization, macroeconomics, and international trade. Review of Economic Studies, 62, 515-539.

Kotler, P. (1997). Marketing management: Analysis, planning, implementation, and control (9th ed.). New Jersey: Prentice Hall.

Leonard-Barton, K. (1992). Core capabilities and core rigidities: A paradox in managing new product development. Strategic Management Journal, 13, 111-125.

Lieberman, M.B., \& Montgomery, D.B. (1988). First-mover advantages. Strategic Management Journal, 9, 41-58.

Porter, M.E. (1980). Competitive strategy: Techniques for analyzing industries and competitors. New York: Free Press.

Porter, M.E. (1985). Competitive advantage: Creating and sustaining superior performance. New York: Free Press.

Porter, M.E. (2001). Strategy and the internet. Harvard Business Review, 79(3), 63-78. 
Raphel, M., \& Raphel, N. (1995). Up the loyalty ladder: Turning sometime customers into full-time advocates of your business. New York: HarperBusiness.

Rumelt, R. (1987). Theory, strategy, and entrepreneurship. In D.J. Teece (Eds.), The competitive challenge: Strategies for industrial innovation and renewal. Cambridge, MA: Ballinger Publishing Co.

Shapiro, C. (2000). Competition policy in the information economy. In Einar Hope (Ed.), Competition Policy Analysis. Routledge Studies in the Modern World Economy.

Shapiro, C., \& Varian, H. (1999). Information rules. Boston, MA: Harvard Business School Press.

Tapscott, D. (1997). Strategy in the new economy. Strategy \& Leadership, 25(6), 8-14.

Vandermerwe, S. (2000). How increasing value to customers improves business results. Sloan Management Review, 42, 27-37.

Williamson, O.E. (1975). Markets and hierarchies: Analysis and antitrust implications. New York: Free Press.

Yoffie, D. (1996). Competing in the age of digital convergence. California Management Review, 38 (4), 31-53. 